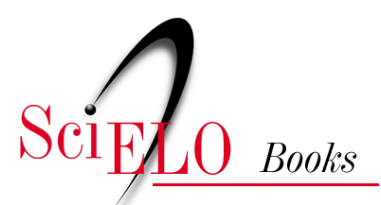

\title{
13. O Machismo na História do Ensino Médico
}

\author{
Joffre Marcondes de Rezende
}

\section{SciELO Books / SciELO Livros / SciELO Libros}

REZENDE, J. M. O Machismo na História do Ensino Médico. In: À sombra do plátano: crônicas de história da medicina [online]. São Paulo: Editora Unifesp, 2009, pp. 131-136. História da Medicina series, vol. 2. ISBN 978-85-61673-63-5. https://doi.org/10.7476/9788561673635.0014.

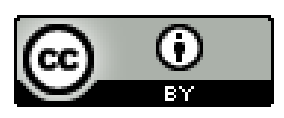

All the contents of this work, except where otherwise noted, is licensed under a Creative Commons Attribution 4.0 International license.

Todo o conteúdo deste trabalho, exceto quando houver ressalva, é publicado sob a licença Creative Commons Atribição 4.0.

Todo el contenido de esta obra, excepto donde se indique lo contrario, está bajo licencia de la licencia Creative Commons Reconocimento 4.0. 


\section{O Machismo na História do Ensino Médico}

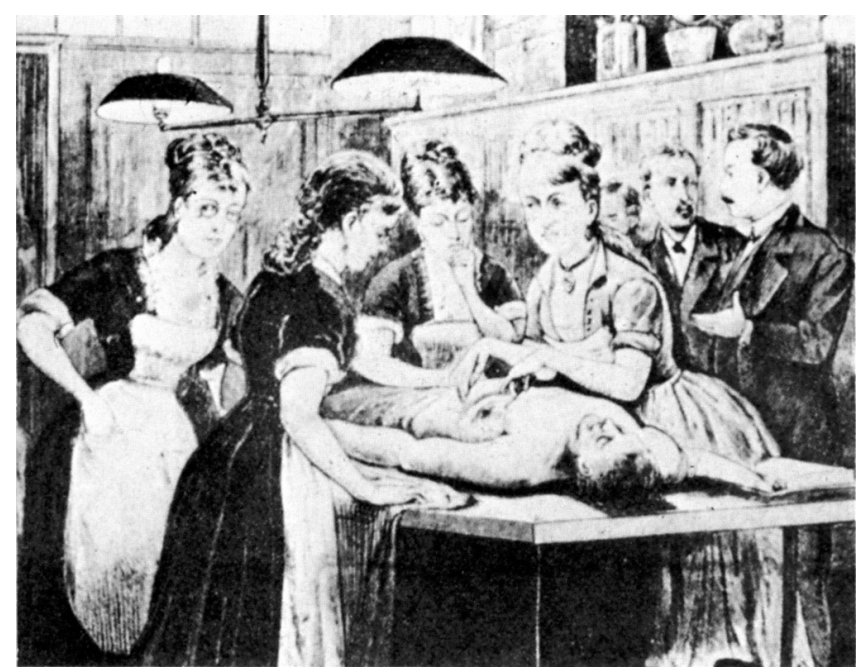

Mulheres estudantes de medicina durante uma dissecção, século XIX.

A medicina, assim como a carreira militar e a eclesiástica, sempre foi atividade considerada própria do sexo masculino. Embora a Escola de Salerno, na Idade Média, admitisse mulheres no curso médico, houve a partir de então uma dificuldade crescente de acesso às universidades para o sexo feminino.

Em relação a medicina, havia ainda o preconceito de que se tratava de uma profissão inadequada à mulher por razões de ordem moral. Quando muito admitia-se a colaboração da mulher no cuidado aos doentes como enfermeira, função exercida durante séculos pelas religiosas de várias ordens (irmãs de caridade), ou na assistência às parturientes, como parteiras.

Em I754, para assombro de toda a Europa, uma alemã, de nome Dorotea Cristina Erxleben, conseguiu o título de doutora em medicina na Universidade de Halle, tendo sido a primeira mulher a receber oficialmente o diploma de médico (Silva, I954, p. I9).

Em I 809, nos Estados Unidos, as primeiras estudantes que se matricularam em um colégio médico, na Pensilvânia, foram motivo de chaco- 
tas, insultos e desrespeito por parte dos estudantes. Na mesma época, em Edimburgo, na Inglaterra, as primeiras moças que conseguiram matrícula no curso médico foram vaiadas, insultadas e agredidas pelos rapazes. A reitoria abriu um inquérito administrativo e decidiu pela expulsão das alunas, considerando-as culpadas pelos distúrbios. A imprensa chamou-as de "as sete sem-vergonha” e uma publicação médica, intitulada Escholastic Medical, escreveu a propósito: "nada há tão materialmente inaceitável como uma doutora em medicina. Se há paradoxo possível é a admissão da mulher na arte de curar. Se Deus tivera adivinhado que a mulher se havia de lembrar uma vez de ser doutora em medicina, certamente, não incomodaria o sono de Adão para lhe tirar a costela" (Idem, pp. I9-20).

Em I 8 I 2 formou-se em Edimburgo um médico de nome James Barry, que ingressou no serviço médico do exército inglês, tendo trabalhado durante muitos anos como médico militar nas colônias inglesas. Era franzino, imberbe e tinha a voz fina. Com a sua morte, em I 865 , descobriu-se que se tratava de uma mulher disfarçada de homem. Para evitar escândalo foi sepultada como homem e só posteriormente o segredo foi revelado. Seguramente inspirada na lenda de Agnodice, foi a maneira encontrada por essa mulher para atender a sua vocação (Lyons e Petrucelli, I978, p. 565).

Apesar de todas as dificuldades encontradas, algumas mulheres destemidas conseguiram pouco a pouco vencer todos os preconceitos e todas as barreiras.

Elizabeth Blackwell, ao tentar matricular-se em um curso médico nos Estados Unidos, teve o seu pedido recusado por onze faculdades e somente foi aceita pelo Genova College, hoje Hobart College, em Nova York. Pela manhã, ao se dirigir às aulas, as outras mulheres se afastavam de seu caminho. Diplomou-se em I 849 e a solenidade de sua formatura atraiu uma multidão de curiosos, que queriam ver a "doutora". Sua irmã, Emily Blackwell, por sua vez, conseguiu matrícula no Rusch Medical College, de Chicago, fato que valeu à escola uma censura da sociedade médica local.

Elizabeth procurou aperfeiçoar-se nos hospitais de Paris e de Londres e foi mal recebida, sendo-lhe permitido frequentar em Paris apenas a maternidade. De volta aos Estados Unidos, juntamente com sua irmã Emily e outra médica alemã, de nome Marie Zakrzewska, fundaram em Nova York um hospital para mulheres e crianças pobres, o New York Infirmary for 
Women and Children. Este hospital franqueou suas instalações a todas as médicas que desejassem frequentá-lo. Nele, também foi criada a primeira escola de enfermagem dos Estados Unidos e se utilizou pela primeira vez um aparelho de raios-X no país. O trabalho pioneiro das irmãs Blackwell foi mais tarde reconhecido (Silva, op. cit., p. 20; Lyons e Petrucelli, op. cit., p. 569).

A liberalização se deu lentamente e com muita resistência. Em I 850 fundou-se em Filadélfia a primeira escola médica para mulheres, The Female Medical College of Pennsylvania. Os professores desta escola eram mal vistos pelos seus colegas e pelas sociedades médicas da época. Seguiram-se outras escolas semelhantes em Boston, New York, Baltimore e Cleveland. Aos poucos, aumentava o número de médicas nos Estados Unidos. Em I 87 I, um editorial da revista Transactions of the American Medical Association comentava: "Uma outra doença está se tornando epidêmica: a questão feminina na medicina é apenas uma das formas pelas quais a pestis mulieribus atormenta o mundo" (Lyons e Petrucelli, op. cit., p. 57I).

O exemplo norte-americano foi seguido por outros países. Em I 873 fundava-se em São Petersburgo, na Rússia, uma escola médica exclusivamente para mulheres, e em I 874 criava-se na Inglaterra a London School of Medicine for Women. A Suíça foi o primeiro país europeu a liberar, em I 876, a matrícula em suas escolas médicas para ambos os sexos e logo outros países fizeram o mesmo (Idem, ibidem).

O Brasil passou a permitir o acesso das mulheres aos cursos superiores, inclusive o de medicina, partir de I879. Apesar das autorizações legais, a tradição cultural e os preconceitos sociais continuavam a opor-se à presença das mulheres na profissão médica.

Em um publicação de $\mathrm{I} 883$, intitulada Apontamentos e Comentários sobre a Escola de Medicina Contemporânea, seu autor, que assinava Leandro Malthus, assim se referiu às estudantes do sexo feminino matriculadas no curso médico: "São desertoras do lar. São, finalmente, os inconscientes arautos que nos vêm mostrar os prenúncios funestos da dissolvência da família" (Maia, I995, p. 6I).

No mesmo ano em que o Brasil abria o curso médico ao sexo feminino, as poucas estudantes que conseguiram matrícula na Faculdade de Medicina de Paris foram duramente maltratadas por seus colegas. 
No alvorecer do século xx, mais precisamente em I905, o kaiser Guilherme II, da Alemanha, ao ser indagado sobre o que pensava do estudo da medicina pelas mulheres, respondeu com ironia: "a mulher deve ocupar-se exclusivamente dos três Ks: Küche, Kirche e Kinder [cozinha, igreja e filhos]" (Silva, op. cit., p. 2I).

No Brasil, a primeira mulher a receber o diploma em medicina foi Maria Augusta Generoso Estrela, natural do Rio de Janeiro. Como em nosso país, até I 879, era vedado o estudo de medicina a moças, dirigiu-se ela aos Estados Unidos em I 875, com apenas I 6 anos de idade, tendo concluído o curso em Nova York, em I 88 I. Retornando ao Brasil em I 882, revalidou o seu diploma na Faculdade de Medicina do Rio de Janeiro, passando a exercer a clínica.

A partir de I 879, com a reforma Leôncio de Carvalho, foi autorizada a matrícula de mulheres nas escolas superiores. A autorização legal, entretanto, em nada mudou a situação, em vista dos arraigados preconceitos sociais contra o curso de medicina.

A partir de $\mathrm{I} 88 \mathrm{I}$ registraram-se algumas matrículas de moças nas duas faculdades de medicina existentes no país: a do Rio de Janeiro e a da Bahia. As três primeiras mulheres a concluir o curso médico no Brasil foram três gaúchas: Rita Lobato Velho Lopes, da cidade de São Pedro do Rio Grande; Ermelinda Lopes de Vasconcelos, natural de Porto Alegre, e Antonieta Cesar Dias, de Pelotas.

As três se matricularam na Faculdade de Medicina do Rio de Janeiro, porém Rita Lobato transferiu-se para a Faculdade de Medicina da Bahia, onde concluiu o curso em I 887. Defendeu tese de doutoramento em 24 de novembro desse ano versando sobre um estudo comparativo das diferentes técnicas utilizadas à época nas operações cesarianas. Ermelinda Vasconcelos formou-se em I888 e Antonieta Cesar Dias em I889, ambas no Rio de Janeiro.

A primeira médica formada no Brasil, portanto, foi Rita Lobato Velho Lopes. A segunda, Ermelinda Vasconcelos, que se dedicou à obstetrícia e chegou a ter uma grande clínica no Rio de Janeiro. Por ocasião de sua formatura mereceu uma crônica do historiador Silvio Romero, sob o título "Machona", que continha as seguintes palavras: "Esteja certo a doutora que os seus pés de machona não pisarão o meu lar”. Tempos depois, a dra. 

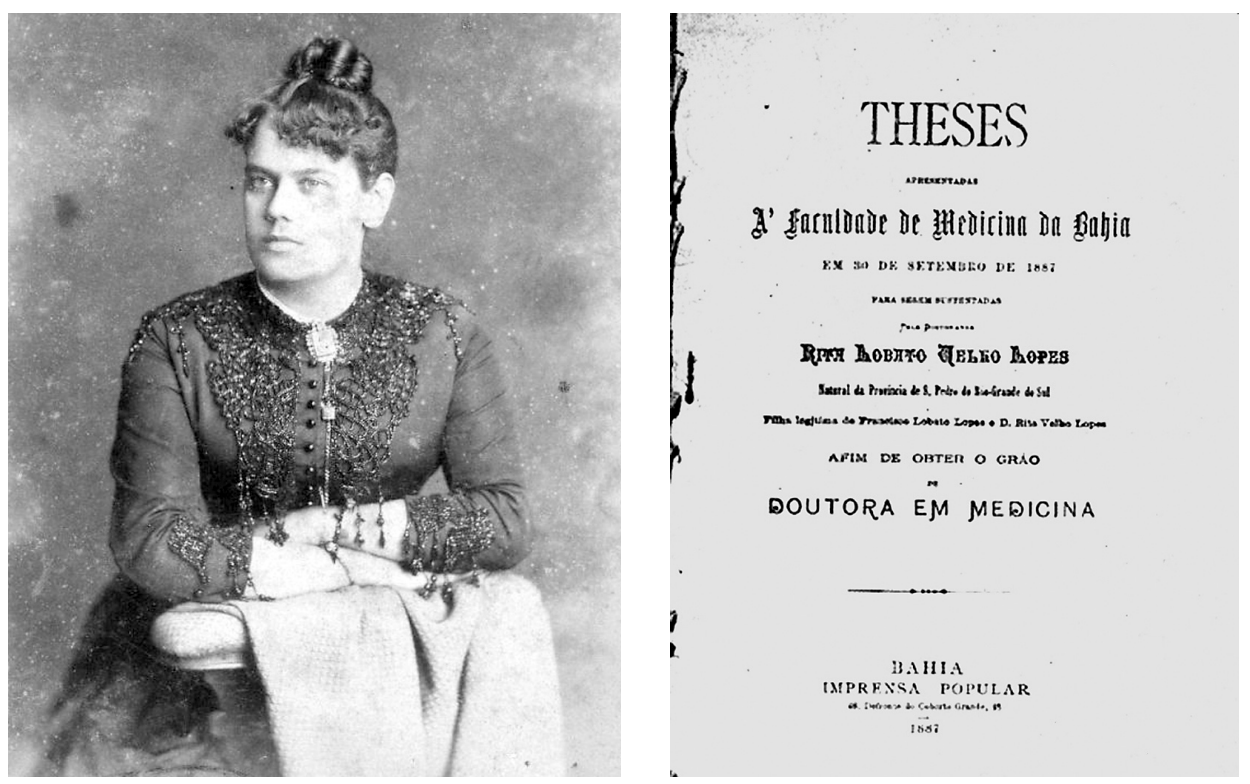

Rita Lobato, a primeira médica formada no Brasil, e sua tese de doutoramento.

Ermelinda foi chamada para fazer o parto da mulher de Silvio Romero. $\mathrm{Na}$ ocasião mostrou-lhe um recorte de jornal que guardava consigo, com a referida crônica (Idem, pp. 5I-6I).

No início do século xx, a atenção mundial era despertada para o fato inédito de uma mulher - Maria Sklodovska Curie - ter ganho o prêmio Nobel de Física em 1903, juntamente com seu marido Pierre Curie. Apesar disso, a Academia de Ciências de Paris recusou-se a admiti-la como membro. Em I9 I I, quando Pierre já não vivia, ganhou sozinha o prêmio Nobel de Química (McGreyne, 1994, pp. 39-40). Era assombroso a mesma mulher ganhar duas vezes o prêmio Nobel: desfazia por completo a ideia generalizada da inferioridade da inteligência feminina - o filósofo Schopenhauer, por exemplo, havia definido a mulher como um ser de cabelos longos e ideias curtas.

Pouco a pouco os espaços foram sendo conquistados e a medicina deixou de ser privilégio dos homens. Figuras notáveis de médicas e pesquisadoras têm surgido nas últimas décadas. Oito mulheres já foram aquinhoadas com o prêmio Nobel de Fisiologia e Medicina: Gerty Cori, em I947; Rosalyn Yallow, em I977; Barbara McClintock, em I983; Rita Levi-Montalcini, em I986; Gertrude B. Elion, em I988; Christiane Nüsslein-Volhard, em I995; 
Linda B. Buck, em 2004; e Françoise Barré-Sinoussi, em 2008, em parceria com Luc Montagnier, pela descoberta do vírus da AIDs.

Um dado expressivo da mudança de mentalidade em nosso país a respeito desta questão pode ser colhido no levantamento realizado, entre I994 e I996, pelo Conselho Federal de Medicina, em parceria com o Instituto Oswaldo Cruz, para avaliação da real situação do médico no Brasil.

Dentre I 84708 médicos pesquisados em todo o território nacional, I 24 I $25(67,2 \%)$ eram homens e $60583(32,8 \%)$ eram mulheres. Quando se considerou a distribuição por sexo e idade, verificou-se que, com idade inferior a 35 anos, havia 50\% de cada sexo (Machado, I999).

\section{Referências Bibliográficas}

Lyons, A. S.; Petrucelli, R. J. Medicine. An Illustrated History. NovaYork, Harry N. Abrams, 1978.

Machado, M. H. Os Médicos no Brasil. Um Retrato da Realidade. Rio de Janeiro, Fiocruz, I999.

Maia, G. D. Biografia de uma Faculdade. Rio de Janeiro, UfRJ, I995.

McGrayne, S. B. Mulheres que Ganharam o Prêmio Nobel em Ciências. São Paulo, Marco Zero, I994.

Silva, A. A Primeira Médica do Brasil. Rio de Janeiro, Irmãos Pongetti Ed., I954. 